\title{
AIDS commission report confounds critics
}

\section{- Emphasis on treatment and research - Almost 200 recommendations made}

Washington

THE US Presidential Commission on the HIV Epidemic surprised observers this week by sending to the White House detailed preliminary recommendations for dealing with the AIDS (acquired immune deficiency syndrome) epidemic that go well beyond the soft approach favoured by the Reagan administration.

The commission's 180 specific recommendations were included in a 60 -page report spelling out three priority areas: intravenous drug abuse treatment; more flexible patient care; and higher priorities for basic research and drug development programmes. The commission originally intended to assess the prevalence of HIV infection in the United States, but this will now be deferred to September.

The 13-member commission issued its recommendations earlier this week after three months of hearings and datagathering. More than 350 witnesses testified, including AIDS patients, health-care practitioners, gay activists, educators, researchers and government agencies.

The keystone of the commission's recommendations for countering intravenous drug abuse is "treatment on demand". There are now roughly $1.2 \mathrm{mil}$ lion intravenous drug users in the United States, but only 148,000 are receiving treatment at any given time. In the 24 cities with the largest numbers of drug abusers, addicts must wait up to six months for treatment. The commission estimates that 3,300 new drug treatment centres will be needed to accommodate these people, with a projected cost of $\$ 1,500$ million. Half of the money is expected to come from the federal government, with the balance being made up by state and local governments.

To address the unique needs of those infected with HIV - who may require only intermittent hospitalization for acute opportunistic infections until they become gravely ill - the commission recommends that available health-care facilities be expanded to include more hospices and outpatient care centres. More trained counsellors, nurses and social workers will be needed, and more emphasis placed on helping minorities.

Nearly half of the commission's recommendations were on basic research and drug development. Specific recommendations include the establishment of regional HIV research centres, a computer network to centralize AIDS research information and new administrative regulations to force the administration to deal rapidly with requests from health agencies.

The commission proposes significant changes for the National Institutes of Health (NIH). Research grants would be restructured to cover longer periods, and the requirement to return money not spent by the end of the grant period would be dropped. Prizes, higher pay-scales and more training programmes would be created at NIH to draw in and retain the best scientific talents. To handle the increased burden, money would be authorized for constructing and equipping new laboratories on the NIH campus, something that has not been done since the late 1960 s. NIH's AIDS reagent repository programme would also be a priority.

The commission recommends that drug development for AIDS should continue to focus on screening existing drugs for antiviral activity, but that more money should be spent on studying what makes a drug effective against HIV. The number of drug reviewers at the US Food and Drug Administration who handle HIV-related products would double to process the increased number of new drug applications. To eliminate the ethically troubling practice of administering placebos in clinical trials of AIDS drugs, an "historic control" database would be created. The commission also recommends clinical trials for studying the effects of proposed AIDS drugs in women, infants and intravenous drug users.

The total $\$ 1,300$ million for AIDS covered in President Reagan's budget request for 1989 (see Nature 331, 646; 1988) will not be enough to pay for these sweeping recommendations. But Congress is likely to embrace many of the suggestions, and its version of the budget may reflect this enthusiasm.

The commission will continue to hold hearings on AIDS-related topics until June. Forthcoming subjects include AIDS prevention and education, discrimination and ethical issues, testing and confidentiality, safety in the workplace, legal concerns, health-care financing and international cooperation.

Carol Ezzell

\section{Superconductivity warning}

ON pages $55-58$ of this issue, the preparation is described of a novel superconductor which includes thallium in its composition. Note that thallium is a toxic substance and appropriate precautions should be taken in its use.

\section{Information body}

Proposals to create a new organization to provide Britain's parliamentarians with "unbiased, high-grade information" on issues of science and technology have moved a step closer to reality. The all-party Parliamentary and Scientific Committee, an unofficial body comprising members of both houses of Parliament, academics and industrialists agreed last week to establish a Parliamentary Science and Technology Foundation. The idea for such a body was first announced late last year (see Nature 330,685 ; 1987).

The organization, which will employ three or four people, will be financed mainly by industry, the government having declined to authorize any money from Parliament's own funds. The body is being set up by senior Conservative backbenchers, unhappy with the present inadequate arrangements for informing rank-and-file members of parliament on topical scientific issues. Timothy Raison, also a Conservative, complained that members of the committee felt its brief was too broad to allow sufficient consideration of the state of British science. He suggested the creation of a new select committee to consider science separately. A more likely option, however, would be to allow the existing committee to set up a scientific subcommittee. S.H.

\section{Britain looks to EC}

BRITAIN's five research councils have set up a joint office in Brussels to improve links with the European Commission and to learn how to tap the commission's research funds more efficiently. The five councils will share the costs of running the office. The research councils have had difficulty in learning about relevant European research programmes at the right time.

S.H.

\section{Superconductor links}

AgreEment was reached last week on measures for improving European cooperation on research into high-temperature superconductivity. Representatives from the research-funding bodies of Britain (SERC), France (CNRS), Italy (CNR) and West Germany (DFG and MPG) met in Paris to discuss ways of implementing a more united approach to the research in order to compete effectively with Japan and the United States. The measures agreed include the free exchange of information on national research priorities and funding arrangements; the exchange of information on facilities and personnel; provision of funding for exchange of postdocs and provision of visiting fellowships; the establishment of a mechanism for disseminating new results before publication; and a method of providing a European basis for the refereeing of major research proposals. 